\title{
THE EFFECT OF TAXIFOLIN ON CISPLATIN INDUCED OXIDATIVE COCHLEAR DAMAGE IN RATS: BIOCHEMICAL AND HISTOPATHOLOGICAL EXAMINATION
}

\author{
ERTUGRUL ERHAN ${ }^{1 *}$, RANA BAYRAM ${ }^{2}$, FERDA KESKIN CIMEN ${ }^{3}$, \\ DURDU ALTUNER ${ }^{4}$, ENDER SECKIN ${ }^{1}$, NEZAHAT KURT ${ }^{5}$ and HALIS SULEYMAN ${ }^{5}$
}

${ }^{1}$ Department of Otorhinolaryngology, Faculty of Medicine, Erzincan Binali Yildirim University, Erzincan-Turkey.

${ }^{2}$ Department of Otorhinolaryngology Mengucekgazi Education and Research Hospital, Erzincan-Turkey ${ }^{3}$ Department of Pathology, Faculty of Medicine, Erzincan Binali Yildirim University, Erzincan-Turkey. ${ }^{4}$ Department of Pharmacology, Faculty of Medicine, Erzincan Binali Yildirim University, Erzincan-Turkey ${ }^{5}$ Department of Biochemistry, Faculty of Medicine, Ataturk University, Erzurum, Turkey.

\begin{abstract}
Ototoxicity of cisplatin is one of the major dose-limiting side effects. Cisplatin-dependent ototoxicity is known to be associated with reactive oxygen species. Protective effect of taxifolin, being a flavanone found in onions, milk thistle, French maritime, and Douglas fir bark, against cisplatin-associated ototoxicity will be examined in this study. There are no studies in the literature examining the protective effect of taxifolin against cisplatin-induced ototoxicity. $50 \mathrm{mg} / \mathrm{kg}$ taxifolin was orally administered to TXC group rats (n-6), and distilled water was orally administered as a solvent to CG (n-6) and HG (n-6) groups. One hour later, $5 \mathrm{mg} / \mathrm{kg}$ cisplatin was administered intraperitoneally (i.p) to TXC and CG groups. This procedure was repeated once a day for 7 days. At the end of this period, all animals were sacrificed by high-dose anesthesia $(50 \mathrm{mg} / \mathrm{kg}$ thiopental sodium) and biochemical and histopathological examinations were performed on the dissected cochlear tissue. Our biochemical test results showed that oxidant parameters were significantly increased whereas antioxidant parameters were significantly decreased in the cisplatin group (CG) compared to taxifolin (TXC) and healthy (HG) groups ( $\mathrm{p}<0.0001$ for both parameters). Histopathological results showed that severe cochlear vestibular membrane degeneration, dilated conjunctival blood vessels, edema and destruction developed in the cisplatin group. However, no pathological findings were found in the taxifolin-treated group except for mild degeneration and edema. This information suggests that taxifolin may be useful in the treatment of cisplatinassociated oxidative cochlear damage.
\end{abstract}

Keywords: taxifolin, cochlear damage, cisplatin, rats

As it is known, cisplatin (cis-diamminedichloroplatinum II) is a widely used platinum derivative anticancer drug which is still valuable in the treatment of many cancer diseases (1). However, the toxic effects of cisplatin on organs and tissues restrict its clinical use. Cisplatin-related ototoxicity is one of the major dose-limiting side effects (2). In $60-80 \%$ of the patients treated with cisplatin, hearing thresholds were increased, and hearing loss was observed in $15 \%$ of the patients $(2,3)$. This information indicates that cisplatin is cochleotoxic. In the literature, it has been reported that cisplatin causes damage to inner and outer hair cells in the cochlea, atrophy in the striae vascularis, collapse of the Reissner membrane and damage to the support cells in the cortis organ (4). These toxic effects due to cisplatin are suggested to be associated with reactive oxygen species (ROS). It is known that cisplatin can produce ROS like hydroxyl radicals and inhibit antioxidant systems (5). It has been reported that cisplatin increases the production of malondialdehyde (MDA) -which is a lipid peroxidation product- in the inner ear and suppresses glutathione (tGSH) production, which is known as an endogenous antioxidant (6). This information indicates that cisplatin creates a toxic effect on the cochlea through oxidative stress. This suggests that antioxidants may be useful in the treatment of cisplatin-associated oxidative cochlear damage.

Taxifolin (3,3', $4^{\text {' }, ~ 5,7-p e n t a h y d r o x i f l a v a n o n) ~}$ examined in this study for its protective effect against cisplatin-associated ototoxicity is a fla-

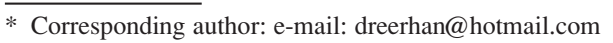


vanone found in onions, milk thistle, French maritime, and Douglas fir bark (7). Previous studies have shown that taxifolin has antioxidant activity (8). There are no studies in the literature examining the protective effect of taxifolin on cisplatin-induced oxidative cochlear damage. Therefore, the aim of our study was to analyze the effect of taxifolin on cisplatin-induced cochlear damage in rats by biochemical and histopathological methods.

\section{EXPERIMENTAL PROCEDURE}

\section{Animals}

In this study, 18 albino Wistar male rats weighing 285-297 grams that were obtained from the medical experimental application and research center of Ataturk University were used. The animals were divided into three groups before the experiment and fed at normal room temperature $\left(22^{\circ} \mathrm{C}\right)$. Animal experiments were performed in accordance with the National Guidelines for the Use and Care of Laboratory Animals and were approved by the local animal ethics committee of Ataturk University, Erzurum, Turkey (Ethics Committee Number: 227 Dated: 27.12.2018).

\section{Chemicals}

Cisplatin CDDP vials $(50 \mathrm{mg} / 100 \mathrm{~mL}$; Cisplatin-Ebewe) were obtained from Liba- Turkey, thiopental sodium was obtained from I.E. UlagayTurkey, and taxifolin was obtained from EvalarRussia.

\section{Experimental groups}

Rats were divided into three groups: Healthy controls (HG), taxifolin+cisplatin (TXC), and cisplatin-treated controls (CG).

\section{Experimental procedure}

$50 \mathrm{mg} / \mathrm{kg}$ taxifolin was orally administered to TXC group rats $(n=6)$, and distilled water was orally administered as a solvent to CG $(n=6)$ and HG $(n=6)$ groups. One hour after taxifolin and distilled water administration, $5 \mathrm{mg} / \mathrm{kg}$ cisplatin was administered intraperitoneally (i.p) to TXC and CG groups. This procedure was repeated once a day for 7 days. At the end of this period, all animals were sacrificed by high-dose anesthesia $(50 \mathrm{mg} / \mathrm{kg}$ thiopental sodium) and their inner ears were removed. Biochemical and histopathological examinations were performed on the dissected cochlear tissue. The results obtained from the taxifolin group were compared with the results obtained from cisplatin and healthy groups and evaluated.

\section{Biochemical analyses}

Prior to dissection, all tissues were rinsed with phosphate-buffered saline solution. The tissues were homogenized in ice-cold phosphate buffers $(50 \mathrm{mM}$, $\mathrm{pH} 7,4)$ that were appropriate for the variable to be measured. The tissue homogenates were centrifuged at 5,000 rpm for $20 \mathrm{~min}$ at $4^{\circ} \mathrm{C}$, and the supernatants were extracted to analyze MDA, tGSH, TAS, TOS and protein concentration. All tissue results were expressed as protein per gram (/g protein). All spectrophotometric measurements were performed using a microplate reader (Bio-Tek, USA).

\section{Malondialdehyde (MDA) analysis}

MDA measurements were based on the method used by Ohkawa et al. involving spectrophotometrical measurement of absorbance of the pink-colored complex formed by thiobarbituric acid (TBA) and MDA. The tissue-homogenate sample $(25 \mu \mathrm{L})$ was added to a solution containing $25 \mu \mathrm{L}$ of $80 \mathrm{~g} / \mathrm{L}$ sodium dodecyl sulfate and $1 \mathrm{~mL}$ mixture solution (200 $\mathrm{g} / \mathrm{L}$ acetic acid $+1.5 \mathrm{~mL}$ of $8 \mathrm{~g} / \mathrm{L}$ 2-thiobarbiturate. The mixture was incubated at $95^{\circ} \mathrm{C}$ for $1 \mathrm{~h}$. Upon cooling, $1 \mathrm{~mL}$ of $\mathrm{n}$-butanol:pyridine $(15: 1)$ was added. The mixture was vortexed for $1 \mathrm{~min}$ and centrifuged for $10 \mathrm{~min}$ at $4000 \mathrm{rpm}$. The absorbance of the supernatant was measured at $532 \mathrm{~nm}$. The standard curve was obtained by using 1,1,3,3-tetramethoxypropane (9).

\section{Total glutathione (tGSH) analysis}

According to the method defined by Sedlak J and Sedlak J, Lindsay RH. DTNB (5,5'-dithiobis [2nitrobenzoic acid]) disulfite is chromogenic in the medium, and DTNB is reduced easily by sulfhydryl groups. The yellow color produced during the reduction is measured by spectrophotometry at 412 $\mathrm{nm}$. For measurement, a cocktail solution $(5.85 \mathrm{~mL}$ $100 \mathrm{mM}$ Na-phosphate buffer, $2.8 \mathrm{~mL} 1 \mathrm{mM}$ DTNB $3.75 \mathrm{~mL} 1 \mathrm{mM}$ NADPH, and $80 \mu \mathrm{L} 625 \mathrm{U} / \mathrm{L}$ Glutathione reductase was prepared. Before measurement, $0.1 \mathrm{~mL}$ meta-phosphoric acid was added to $0.1 \mathrm{~mL}$ tissue-homogenate and centrifuged for $2 \mathrm{~min}$ at $2000 \mathrm{rpm}$ for deproteinization. The $0.15 \mathrm{~mL}$ cocktail solution was added to $50 \mu \mathrm{L}$ of supernatant. The standard curve was obtained by using GSSG (10).

\section{Measurements of TOS and TAS}

TOS and TAS levels of tissue homogenates were determined using a novel automated measurement method and commercially available kits (Rel Assay Diagnostics, Turkey), both developed by Erel O $(11,12)$. The TAS method is based on the bleaching of characteristic color of a more stable ABTS 
(2,2'-azino-bis (3-ethylbenzothiazoline-6-sulfonic acid) radical cation by antioxidants and, measurements is performed $660 \mathrm{~nm}$. The results are expressed as nmol hydrogen peroxide $\left(\mathrm{H}_{2} \mathrm{O}_{2}\right)$ equivalent/L. In TOS method, the oxidants present in the sample oxidized the ferrous ion-o-dianisidine complex to ferric ion. The oxidation reaction was enhanced by glycerol molecules, which are abundantly present in the reaction medium. The ferric ion produced a colored complex with xylenol orange in an acidic medium. The color intensity, which could be measured at $530 \mathrm{~nm}$ spectrophotometrically, was related to the total amount of oxidant molecules present in the sample. The results are expressed as $\mu$ mol Trolox equivalent/L. The percentage ratio of TOS to TAS was used as the oxidative stress index (OSI). OSI was calculated as TOS divided by $100 \times$ TAS .

\section{Histopathological evaluation}

After routine tissue follow-up, $5 \mu \mathrm{m}$ thick sections were obtained for histopathological evaluation. These sections were stained with HematoxylinEosin ( $\mathrm{H} \& \mathrm{E})$, and the cochlear tissues were evaluated under light microscopy (Olympus BX 51, Japan) by a pathologist blinded to the treatment protocol. All images were obtained with a digital camera (Olympus DP 71).

\section{Statistical analyses}

The results obtained from the experiments were expressed as" mean \pm standard deviation" ( $\mathrm{x} \pm$
SD). The significance of the difference between the groups was determined by one-way ANOVA. Fisher's post-hoc LSD (least significant differences) test was performed afterward. All statistical procedures were performed in "IBM SPSS Statistics Version 20" statistical program and $\mathrm{p}<0.05$ was considered significant.

\section{RESULTS AND DISCUSSION}

\section{Biochemical results}

As shown in Figure 1A, the amount of MDA in the cochlea tissue of the animals treated with cisplatin was significantly higher compared to the healthy and taxifolin groups $(\mathrm{p}<0.0001)$. The amounts of MDA in the cochlea tissue of healthy animals and animals treated with taxifolin were very close to each other and the difference was statistically insignificant $(\mathrm{p}>0.05)$.

Cisplatin administration caused a decrease in the amount of tGSH in the cochlea tissue of the animals. Taxifolin prevented the decrease in tGSH due to cisplatin in the cochlear tissue of animals ( $p<$ 0.0001 ). The difference between the amount of tGSH in taxifolin and the healthy group was statistically insignificant (Fig. 1B) $(\mathrm{p}>0.05)$.

TOS level was significantly higher in cochlear tissue of the cisplatin group compared to the taxifolin group and the healthy group (Fig. 1C) (p < $0.0001)$, whereas TAS level was significantly lower ( $\mathrm{p}<0.0001)$. The difference in TOS and TAS levels between the taxifolin and healthy group
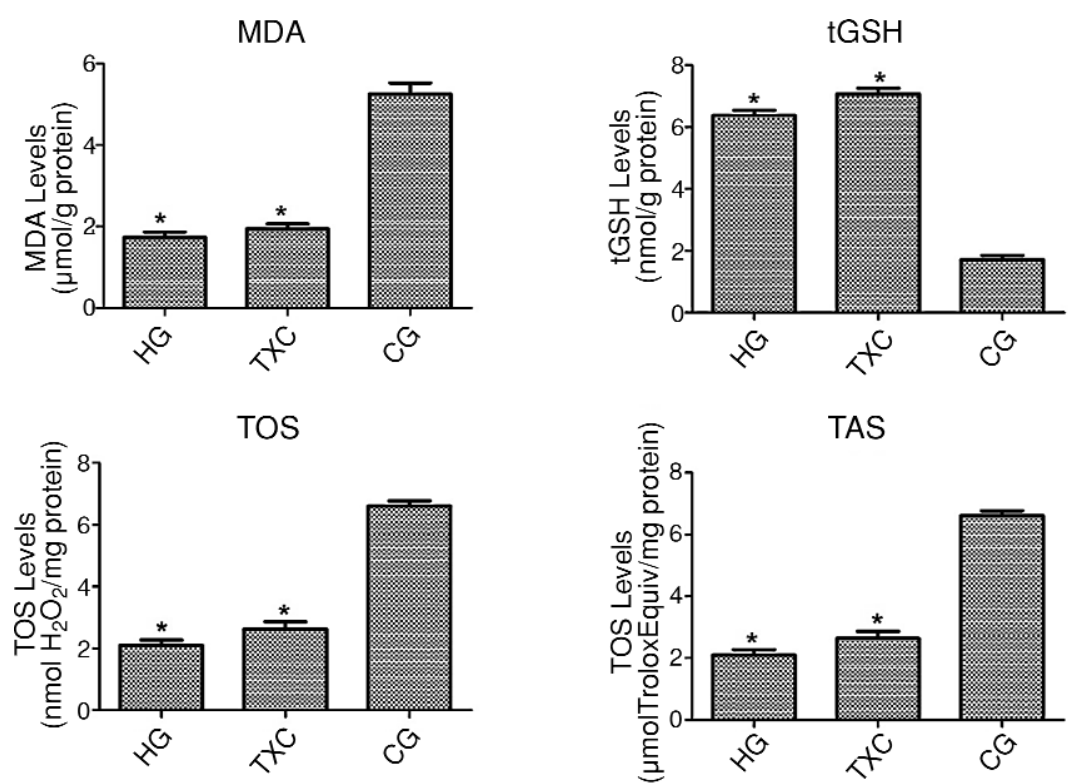

Figure 1. Oxidant/ antioxidant levels of cochlear tissue in study groups $* \mathrm{p}<0.0001$ according to CG group 
was found to be statistically insignificant (Fig. 1D) $(\mathrm{p}>0.05)$.

\section{Histopathological Results}

Figure 2A shows the normal cochlea tissue of the healthy group. In the cisplatin group, severe cochlear vestibular membrane degeneration, dilated conjunctival blood vessels, edema and destruction were detected (Fig. 2B). However, no pathological findings were found in the taxifolin-treated group except for mild degeneration and edema (Fig. 2C). In this study, the effect of taxifolin on cisplatininduced cochlear damage in rats was examined biochemically and histopathologically. As it is known, ototoxic damage due to cisplatin occurs in all cochlear structures (outer and inner hair cells, Corti organs, and stria vascularis) (13). Recent studies have reported that cisplatin produces an ototoxic effect on the cochlea by increasing ROS production and reducing antioxidant enzyme activity (14). As stated in the literature, ROSs react with lipids in the cell membrane to induce lipid oxidation (LPO). LPO is the process of reactions that cause damage to organs and tissues (15). MDA, which is formed as a result of LPO and known as the final product of LPO, is involved in exacerbating cell membrane damage (16). In their studies, Peters et al. reported that cisplatin accelerated LPO reaction in cochlear tissue cells (17). Furthermore, it was reported that the amount of MDA, which is the product of LPO, increased in cochlear tissue (18).

As can be understood from our biochemical test results, significant histopathological destruction, dilated conjunctival blood vessels, edema and vestibular membrane degeneration were observed in the cochlea tissue of the cisplatin group with high MDA levels. Kilic et al. showed that cisplatin-related oxidative stress caused histopathological damage such as destruction, degeneration, edema in cochlear tissue cells and erosion in stria vascularis (19). In the cochlea tissue of the taxifolin group, which had a significantly lower MDA amount compared to the cisplatin group, histopathological appearance was close to normal except for edema and mild degeneration. This means that taxifolin inhibited LPO reaction and suppressed oxidative stress. There are no studies in the literature on the effect of taxifolin on LPO in cochlear tissue. However, recent studies have shown that taxifolin inhibits MDA increase in blood serum and heart tissue $(20,21)$. This information obtained from the literature shows that previous studies support the results of our biochemical and histopathological experiments.

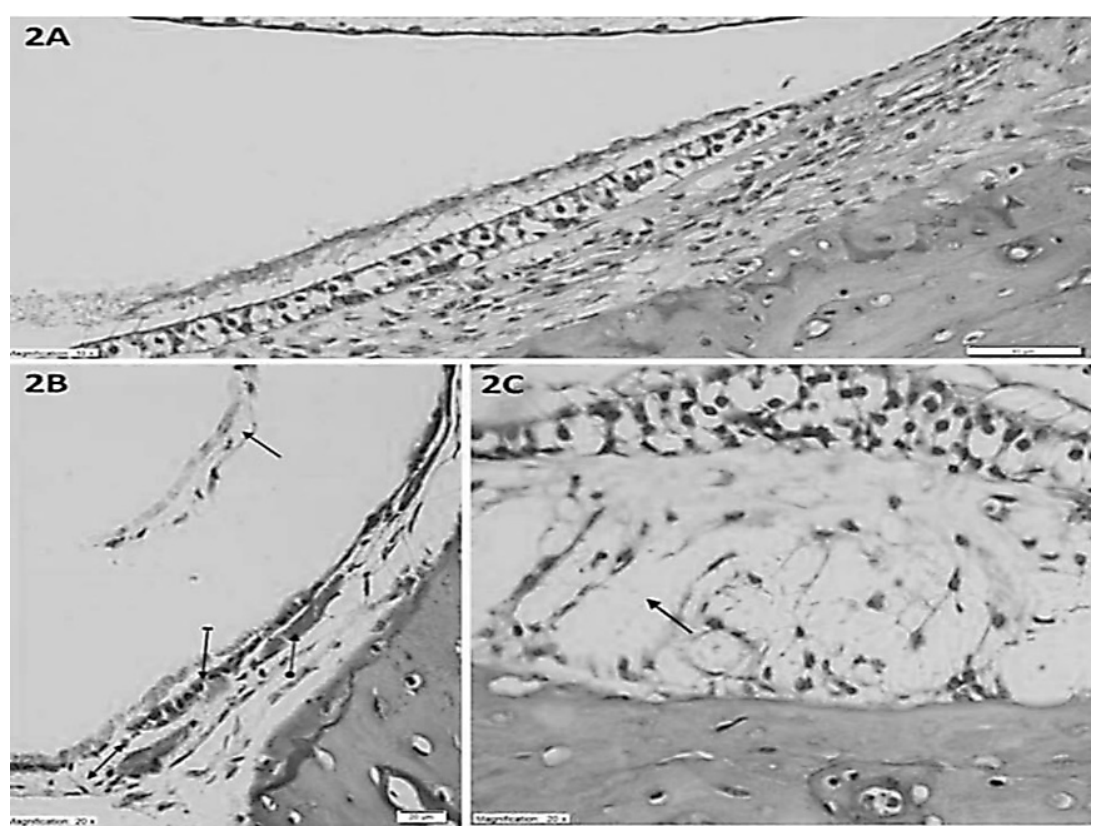

Figure 2. Histopathological appearance of cochlear tissue in study groups 2A. Healthy cochlear tissue in the HG group (HEX 200). 2B. Section showing cochlear vestibular membrane degeneration (straight arrow), dilated conjunctival blood vessel (rounded arrow), edema (double-sided arrow) and destruction (striated arrow) in the Cisplatin treated CG group (HEX 400). 2C. Section showing edema and mild degeneration of the cochlea in the TXC group treated with taxifolin (HEX 400). 
It is noted in the literature that there is still no specific treatment that eliminates the ototoxic effect of cisplatin. For this reason, trials are being conducted with many antioxidant drugs to prevent and treat cisplatin ototoxicity. In this study, we investigated the effect of taxifolin against cisplatin-induced oxidative cochlear damage and found that taxifolin prevented the decrease of $\mathrm{tGSH}$ with cisplatin and development of histopathological damage in cochlear tissue. This suggests that histopathological damage in cochlear tissue may be associated with inhibition of tGSH production. It has been proposed that tGSH and other enzymatic and non-enzymatic antioxidants protect the cochlea from oxidative damage of ROSs (18). In addition, GSH storage is higher in cochlear outer hair cells and this may explain the role of GSH in the pathogenesis of cisplatin-induced cochlear toxicity (22). However, some studies have reported that antioxidant drugs that reduce cisplatin toxicity may also decrease the anticancer activity of cisplatin (23, 24). Taxifolin has been shown to have a strong anticancer effect as being a potent antioxidant molecule $(25,26)$. This shows that taxifolin has an important feature in preventing cisplatin ototoxicity.

\section{CONCLUSIONS}

In our study, it was also found that taxifolin antagonized the effects of cisplatin on TOS and TAS in cochlear tissue. No studies were found in the literature investigating the effect of cisplatin on TOS and TAS levels in cochlear tissue. TOS, which we used to assess the toxic effect of cisplatin on cochlea, is used to determine the cumulative oxidative effects of various oxidants in biological systems (12). On the other hand, TAS is used to evaluate the total antioxidant capacity of different antioxidant molecules in tissue (11). The balance between this oxidant and antioxidant capacity determines the susceptibility of organs and tissues to oxidative stress (27). As a result, the oxidant-antioxidant balance in the Cisplatin group changed in favor of oxidants. However, taxifolin prevented this cisplatin-induced shift in oxidant antioxidant balance in favor of oxidants in cochlear tissue. Biochemical and histopathological investigations revealed that taxifolin inhibited cisplatin-induced oxidative damage in cochlear tissue. This information suggests that taxifolin may be useful in the treatment of cisplatinassociated oxidative cochlear damage.

\section{Conflict of interest}

The authors declare no conflicts of interest.

\section{REFERENCES}

1. Sakamoto M., Kaga K., Kamio T.: Otolaryngol. Head Neck Surg. 122, 828 (2000).

2. Cooley M.E., Davis L., Abrahm J.: Cancer Nurs. 17, 283 (1994).

3. Blakley B.W., Gupta A.K., Myers S.F., Schwan S.: Arch. Otolaryngol. Head Neck Surg. 120, 541(1994).

4. Laurell G., Bagger-Sjoback D.: J. Otolaryngol. 20, 158 (1991).

5. Fetoni A.R., Sergi B., Ferraresi A., Paludetti G., Troiani D.: Acta Otolaryngol. 124, 421 (2004).

6. Kuduban O., Kucur C., Sener E., Suleyman H., Akcay F.: Scientific World Journal 2013, ID 182694, 5 pages (2013).

7. Wang Q., Wang L., Li G., Ye B.: Talanta 164, 323 (2017).

8. Topal F., Nar M., Gocer H., Kalin P., Kocyigit U.M. et al.: J. Enzyme Inhib. Med. Chem. 31, 674 (2016).

9. Ohkawa H., Ohishi N., Yagi K.: Anal. Biochem. 95, 351 (1979).

10. Sedlak J., Lindsay R.H.: Anal. Biochem. 25, 192 (1968).

11. Erel O.: Clin. Biochem. 37, 112 (2004).

12. Erel O.: Clin. Biochem. 38, 1103 (2005).

13. Hinojosa R., Riggs LC., Strauss M., Matz G.J.: Am. J. Otol. 16, 731 (1995).

14. Youn C.K., Kim J., Jo E.R., Oh J., Do N.Y., Cho S.I.: Int. J. Mol. Sci. 17, 1931 (2016).

15. Davies K.J.A., Goldberg A.L.: J. Biol. Chem. 262, 8220 (1987).

16. Goulart M., Batoreu M.C., Rodrigues A.S., Laires A., Rueff J.: Mutagenesis 20, 311 (2005).

17. Peters R.C., Mommersteeg P.M., Heijmen P.S.: Neuroscience 91, 745 (1999).

18. García-Berrocal J.R., Nevado J., RamírezCamacho R., Sanz R., González-García J.A. et al.: Br. J. Pharmacol. 152, 1012 (2007).

19. Kilic K., Sakat M.S., Akdemir F.N.E., Yildirim S., Saglam Y.S., Askin S.: Braz. J. Otorhinolaryngol. 85, 267 (2018).

20. Ahiskali I., Pinar C.L., Kiki M., Mammadov R., Ozbek Bilgin A. et al.: Cutan. Ocul. Toxicol. doi: 10.1080/15569527.2019.1588289, 6 pages (2019).

21. Tang Z., Yang C., Zuo B., Zhang Y., Wu G. et al.: Peer J. 7, e6383 (2019)

22. Rybak L.P., Husain K., Morris C., Whitworth C., Somani S.: Am. J. Otol. 21, 513 (2000).

23. Muldoon L.L., Pagel M.A., Kroll R.A., Brummett R.E., Doolittle N.D. et al.: Clin. Cancer Res. 6, 309 (2000). 
24. Neuwelt E.A., Pagel M.A., Hasler B.P., Deloughery T.G., Muldoon L.L.: Cancer Res. 61, 7868 (2001).

25. Haque M.W., Pattanayak S.P.: Pharmacogn. Mag. 13, 749 (2018).
26. Chen X., Gu N., Xue C., Li B.R.: Mol. Med. Rep. 17, 3239 (2018)

27. Serafını M., Del Rio D.: Redox Rep. 9, 145 (2004).

Received: 18.04 .2019 